Journal of the Operations Research Society of Japan

Vol. 29, No. 3, September 1986

\title{
ON G/G/1 QUEUES WITH LIFO-P SERVICE DISCIPLINE
}

\author{
J. George Shanthikumar \\ University of California Berkeley
}

\author{
Ushio Sumita \\ University of Rochester
}

(Received September 25, 1985: Revised March 27, 1986)

\begin{abstract}
We consider a single server queueing system $\mathrm{G} / \mathrm{G} / 1$ having general interarrival times (not necessarily i.i.d), i.i.d. service times, and LIFO-P (preemptive last in first out, but not restricted to resumption) service disciplines. Furthermore a customer finding $n$ other customers in system upon his arrival joins the system with probability $p(n)$ and immediately leaves the system with probability $1-p(n)$, where $0 \leq p(n) \leq 1$. The relations among various ergodic probabilities of the number of customers in system are established via sample path arguments. Sufficient conditions are given for the customer average ergodic probability distribution to be geometric, thereby extending recent results of Fakinos (1981) and Yamazaki $(1982,1984)$.
\end{abstract}

Key words: G/G/1 queues, preemptive last in first out service discipline, geometric distribution, stochastic ordering

\section{Introduction}

A GI/G/1 queueing system can be characterized by two independent sequences of i.i.d. random variables $\left(\Delta_{i}\right)$ and $\left(s_{i}\right)$ denoting interarrival times and service times respectively together with an underlying service discipline. In recent papers by Fakinos (1981) and Yamazaki (1982, 1984), interesting results have been obtained for GI/G/1 queueing systems with LIFO-P/R (last in first out with preempt/resume) service discipline (also see Cooper and Niu (1986)). More specifica11y, let $\left(e_{n}\right)$ and $\left(r_{n}\right)$ be the ergodic probabilities of the number of customers in system averaged over time and averaged over the number of arrivals respectively. It has been shown by Yamazaki (1984) that

(1.1) $\quad e_{n+1}=\rho r_{n}, \quad n=0,1,2, \ldots$,

where $\rho=E[S] / E[\Delta]$ and $0<\rho<1$. Fakinos (1981) and Yamazaki (1982) have

shown that $r_{n}$ (and hence $\left(\frac{1}{1-\rho} e_{n}\right)_{n=1}^{\infty}$ ) is a geometric distribution given by 


$$
r_{n}=(1-\sigma) \sigma^{n}, \quad n=0,1,2, \ldots,
$$

where $\sigma=1-\left(E(S) / E\left(T_{B P}\right)\right)$ and $T_{B P}$ is the server busy period of the underlying GI/G/1 queueing system, For GI/G/1, it should be noted that $T_{B P}$ is not affected by any work conserving service disciplines. Furthermore, it has been shown in Yamazaki (1984) that:

(1.3) The joint distribution of the remaining service requirement of the customer in service and the number of customers in system at ergodicity takes a product form, i.e. the two distributions are independent.

The main purpose of this paper is to establish these results in a more general context based on an entirely different approach - a sample path argument. As we will see this approach parovides short and simple proofs for (1.1) through (1.3). Some results regarding the stochastic ordering of single server queueing system with LIFO-P/R and FIFO service disciplines are also obtained.

\section{Extension of Results of Fakinos and Yamazaki via Sample Path Approach}

We consider a single server queueing system described by the following characteristics:

$$
\begin{aligned}
& \left(A_{i}\right)_{i=1}^{\infty} \\
& \left(S_{i}\right)_{i=1}^{\infty}
\end{aligned}
$$$$
\text { a sequence of random arrival epochs; }
$$

a sequence of i.i.d. random variables with $S_{i}$ denoting the service time of the $i$-th customer; $\left(S_{i}\right)_{i=1}^{\infty}$ and $\left(A_{i}\right)_{i=1}^{\infty}$ are independent of one another;

(2.3) LIFO - P/R the last in first out preempt/resume service discipline; A customer finding $n$ customers in system (excluding himself) upon his arrival is either accepted to the system with probability $p(n)$ or immediately leaves the system with probability $1-p(n), 0 \leq p(n) \leq 1$; The system is ergodic.

As we will see, LIFO-P service disciplines (not restricted to resumption) can be treated when $p(n)=p, n \geq 0$.

We note that $\Delta_{i+1}=A_{i+1}-A_{i}, i=1,2, \ldots$, are not required to be i.i.d. Furthermore such a system with finite system capacity $K$ can be incorporated by setting $p(n)=0, n \geq K$. It should also be noted that, because 
of (2.4), the busy period of this queueing system need not be probabilistically the same as that under FIFO service discipline, see Shanthikumar and Sumita (1985a).

Let $N(t)$ be the number of customers in the system at time $t$ and let $I_{(P(x))}$ be the indicator function taking the value one when the statement $P(x)$ holds true and zero otherwise. We denote a sequence of customer departure epochs by $\left(D_{j}\right)_{j=1}^{\infty}$. The counting process associated with $\left(A_{i}\right)_{i=1}^{\infty}$ and $\left(D_{j}\right)_{j=1}^{\infty}$ are denoted by $V(t)$ and $W(t)$ respectively. Let $\delta_{i}$ be the indicator function where $\delta_{i}$ is equal to one if the $i$-th arriving customer is accepted to the system and zero otherwise. Accordingly, the number of customers accepted to the system during $(0, t]$ is $z(t)=\sum_{i=1}^{V(t)} \delta_{i}$. Of interest are the stochastic processes defined, with the notation $N^{-}=N\left(A_{i^{-}}\right)$and $N_{j}^{+}=N\left(D_{j^{+}}\right)$, by

$$
\begin{aligned}
& e_{n}(t)=\frac{1}{t} \int_{0}^{t} I(N(\tau)=n) d \tau, \\
& r_{n}(t)=\frac{1}{2(t)} \sum_{i=1}^{V(t)} I_{\left(N_{i}=n\right)} \delta_{i},
\end{aligned}
$$

$$
f_{n}(t)=\frac{1}{V(t)} \sum_{i=1}^{V(t)} I_{\left(N_{i}^{-}=n\right)}
$$

$$
g_{n}(t)=\frac{1}{V(t)-2(t)} \sum_{i=1}^{V(t)} I_{\left(N_{i}^{-}=n\right)}\left(1-\delta_{i}\right)
$$

and

$$
q_{n}(t)=\frac{1}{W(t)} \sum_{i=1}^{W(t)} I\left(N_{j}^{+}=n\right)
$$

From the assumption (2.5) al1 of these processes converge to nonnegative constants with probability one as $t \rightarrow \infty$ for $n \geq 0$. These constants are denoted by $e_{n}, r_{n}, f_{n}, g_{n}$ and $q_{n}$, where they represent ergodic probabilities of the number of customers in the system, averaged over: time, the number of accepted. arrivals, the number of arrivals, the number of rejected arrivals, and the number of departures, respectively,

One observes that the actual arrival rate $\lambda$ at ergodicity is given by

$$
\lambda=\lim _{t \rightarrow \infty} V(t) / t
$$

Similarly the effective arrival rate $\lambda *$ at ergodicity is found as

$$
\lambda *=\lim _{t \rightarrow \infty} Z(t) / t
$$


Then the ratio

$$
p^{*}=\frac{\lambda *}{\lambda}=\lim _{t \rightarrow \infty} \frac{Z(t)}{V(t)}
$$

is the effective acceptance probability of an arriving customer at ergodicity. We note from (2.7) through (2.9) that

$$
f_{n}(t)=\frac{z(t)}{V(t)} r_{n}(t)+\left(1-\frac{z(t)}{V(t)}\right) g_{n}(t) \text {. }
$$

By letting $t \rightarrow \infty$, one has

$$
r_{n}=\frac{1}{p^{*}}\left(f_{n}-g_{n}\left(1-p^{*}\right)\right), \quad n \geq 0
$$

It can be seen from (2.7) and (2.10) that $r_{n}(t) z(t)$ and $q_{n}(t) W(t)$ differ by at most one since these two entities represent the number of upcrossings and the number of downcrossings of $N(t)$ at the level $n$. Hence one has

(2.15) $\quad r_{n}=q_{n}, \quad n \geq 0$.

The results in $(2.14)$ and (2.15) have been shown in a more general context in Shanthikumar and Chandra (1982). We now prove the following theorem extending $(1.1)$.

Theorem 2.1.

$$
e_{n+1}=\lambda * E[S] r_{n}, \quad n \geq 0
$$

Proof: Since the LIFO-P/R service discipline is assumed, there are exactly $n+1$ customers in the system whenever a customer who found $n$ customers in system upon his arrival is in service. Hence one has

$$
\int_{0}^{t} I(N(\tau)=n+1) d \tau=\sum_{i=1}^{V(t)} I_{\left(N_{i}^{-}=n\right)} \delta_{i} S_{i}-R_{n}(t), \quad n \geq 0,
$$

where $R_{n}(t)$ is the remaining service time of the last customer who arrived before $t$ and found $n$ customers in system upon his arrival if $N(t) \geq \mathrm{n}+1$, and is zero otherwise. From (2.6) it follows that

$$
e_{n+1}(t)=\frac{V(t)}{1} \cdot \frac{1}{V(t)}\left\{\sum_{i=1}^{V(t)} I_{\left(N_{i}^{-}=n\right)} \delta_{i} s_{i}-R_{n}(t)\right\}, \quad n \geq 0 .
$$

Clearly random variables $I_{\left(N_{i}^{-}=n\right)} \cdot \delta_{i}$ and $S_{i}$ are mutually independent. Furthermore, $R_{n}(t)$ is an honest random variable for all $t$ and $V(t) \rightarrow \infty$ as $t \rightarrow \infty$ almost surely. Hence from the ergodic theory and (2.11), one has 


$$
\begin{gathered}
\lim _{t \rightarrow \infty} e_{n+1}(t)=\lambda \cdot E\left[I_{\left(N_{\infty}^{-}=n\right)} \delta_{\infty} S_{\infty}\right] \\
=\lambda \cdot E\left[I_{\left(N_{\infty}^{-}=n\right)} \delta_{\infty}\right] E[S] .
\end{gathered}
$$

It can be seen from the ergodic theory, (2.7) and (2.13), that

$$
\begin{gathered}
E\left[I_{\left(N_{\infty}^{-}=n\right)} \delta_{\infty}\right]=\lim _{t \rightarrow \infty} \frac{1}{V(t)} \sum_{i=1}^{V(t)} I_{\left(N_{i}^{-}=n\right)} \delta_{i} \\
=\lim _{t \rightarrow \infty} \frac{Z(t)}{V(t)} \cdot r_{n}(t)=\frac{\lambda *}{\lambda} r_{n} .
\end{gathered}
$$

Substituting this into (2.17), one finds that $e_{n+1}=\lambda *_{E}[S] r_{n}$, completing the proof.

We next extend (1.2) assuming $\left(\Delta_{i}\right)$ are $i . i . d$. and $p(n)=p, n \geq 0$. However we allow more general preemptive service disciplines. We cal1 a preemptive service discipline LIFO-P/H if the service discipline is preemptive LIFO with any restarting policy that depends on the history of preemptions, e.g. preemptive repeat, or variable service rate as a function of the number of reentries into service, etc. Under such a policy we denote the actual service time of the $i-t h$ customer by $s_{i}^{a c t}$ provided he is accepted. We also define the effective service time $S_{i}^{e f f^{I}}$ as the elapsed time from the first entry into service until the departure of the $i$-th customer. We note that $s_{i}^{a c t}, i=1,2, \ldots\left(s_{i}^{e f f},=1,2, \ldots\right)$ may not be independent but are identically distributed. Furthermore

(2.18) $S_{i}^{a c t}$ and $S_{i}^{e f f}$ are independent of $\left\{N(t), 0 \leq t \leq A_{i}\right\}$.

Therefore it is clear that $S^{\text {eff }}$ is equal in distribution to $T_{B P}^{*}$ where $T_{B P}^{*}$ is the server busy period of the underlying queueing system. The asterisk is used because a LIFO-P/H policy may not be work conserving.

Theorem 2.2. Let $\left(\Delta_{i}\right)$ be i.i.d., $p(n)=p, n \geq 0$, and let the service discipline be LIFO-P/H as described above. Then:
(a) $e_{n+1}=\lambda * E\left[s^{a c t}\right] x_{n}, \quad n \geq 0$,
(b) $\sum_{\ell=n+1}^{\infty} e_{\ell}=\lambda^{*} E\left[T_{B P}^{*}\right] r_{n}, \quad n \geq 0$,
(c) $r_{n}=(1-\sigma) \sigma^{n}, \quad n \geq 0$, 
where $\sigma=1-\left(E\left[S^{a c t}\right] / E\left[T_{B P}^{*}\right]\right)$.

Proof: For (a), we note that Equation (2.16) is valid under the conditions of the theorem provided that $\left(s_{i}\right)$ are replaced by $\left(S_{i}^{a c t}\right)$. From $(2.18)$ $I_{\left(N_{i}^{-}=n\right)} \cdot \delta_{i}$ and $S_{i}^{\text {act }}$ are mutually independent. As in $(2.17)$, the decomposition of (2.16) in taking a limit is therefore justified and statement (a) follows.

As for the LIFO-P/R service discipline, any LIFO-P/H service discipline assures that there are at least $(n+1)$ customers in the system as long as a customer who found $n$ customers in system uppn his arrival remains in system. Hence one has

$$
\sum_{\ell=n+1}^{\infty} e_{\ell}(t)=\frac{V(t)}{t} \cdot \frac{1}{V(t)}\left\{\sum_{i=1}^{V(t)} I_{\left(N_{i}^{-}=n\right)} \delta_{i} S_{i}^{\text {eff }}-R_{n}^{\text {eff }}(t)\right\}, n \geq 0,
$$

where $R_{n}^{\text {eff }}(t)=\inf \{\tau: N(t+\tau) \leq n, \tau \geq 0\}$. Since $S_{i}^{\text {eff }} \stackrel{d}{=} T_{B P}^{*}$, statement $(\mathrm{b})$ follows from (2.19) by letting $t \rightarrow \infty$.

For (c), we observe from (a) and (b) that

$$
\lambda * E\left[S^{a C t}\right] r_{n}=e_{n+1}=\lambda * E\left[T_{B P}^{*}\right]\left(r_{n}-r_{n+1}\right) .
$$

This then leads to

$$
r_{n+1}=\left(1-\frac{E\left[S^{a C t}\right]}{E\left[T_{B P}^{*}\right]}\right) r_{n}=\sigma^{n} r_{0} \text {. }
$$

Since $\sum_{n=0}^{\infty} r_{n}=1$, one has $r_{0}=(1-\sigma)$, completing the proof.

Remark 2.3. In the case of the work conserving (LIFO-P/R) service discipline, one has $E\left[S^{a c t}\right]=E[S]$ and in addition $E\left[T_{B P}^{*}\right]=E\left[T_{B P}\right]$ when $p(n)=n$, $n \geq 0$. Then Theorem 2.2 (c) coincides with (1.2). For certain single server queues such as $\mathrm{GI} / \mathrm{PH} / 1$ or $\mathrm{PH} / \mathrm{G} / 1$, an algorithmic procedure is available for computing $E\left[T_{B P}\right]$, see Neuts (1981) and Ramaswami (1982). Consequently both $\left(r_{n}\right)_{n=0}^{\infty}$ and $\left(e_{n}\right)_{n=0}^{\infty}$ can be readily obtained. Even for more general cases, once the value of $\sigma_{0}=1-\sigma$ is estimated via simulation, the other probabilities can be calculated. Alternatively one may use the geometric distribution to control the error while estimating the probabilities $\left(r_{n}\right)$ using simulation.

We next turn our attention to (1.3). Consider a single server queueing system as in the context of Theorem 2.1. Let $R^{*}(t)$ be the remaining service time of the customer currently in service at time $t$. Then $R^{*}(t)=R_{N(t)-1}(t)$, since: 
customer currently in service at time $t$ when there are $N(t)=n$ customers in the system must have seen $n^{-1}$ customers in system upon his arrival.

For the bivariate process $\left(R^{*}, N\right) \equiv\left\{\left(R^{*}(t), N(t)\right), t \geq 0\right\}$, define

$$
\bar{H}_{R, N}(x, n, t)=\frac{1}{t} \int_{0}^{t} I\left(R^{*}(\tau)>x, N(\tau)=n\right) d \tau, \quad x \geq 0, n \geq 1,
$$

and its limit as $t \rightarrow \infty$ by $\bar{H}_{R, N}(x, n)$. Note that by assumption (2.5), the above limit exists. Clearly $\vec{H}_{R, N}$ is the joint ergodic survival function of the remaining service time of the customer in service and the probability distribution of the number of customers in the system averaged over time. One then has the following theorem:

Theorem 2.4.

$$
\bar{H}_{R, N}(x, n)=\frac{E\left[\{S-x\}^{+}\right]}{E[S]} e_{n}, \quad x \geq 0, n \geq 1,
$$

where $\{x\}^{+} \equiv \max \{x, 0\}$.

Proof: Suppose the $i$-th customer on its arrival sees $n^{-1}$ customers in the system and it is accepted to the system. It is clear that the total amount of time during which the remaining service time of the $i$-th customer while in service is greater than $x$ is $\left\{s_{i}-x\right\}^{+}$. Then noting that $t \bar{H}_{R, N}(x, n, t)$ is the total time in $[0, t)$, during which the remaining service time of the customer in service is greater than $x$ and the number of customers in the system is $n$, one has from $(2.20)$,

$$
\bar{H}_{R, N}(x, n, t)=\frac{1}{t}\left\{\sum_{i=1}^{V(t)} I_{\left(N_{i}^{-}=n^{-1}\right)} \delta_{i}\left\{S_{i}^{-x\}^{+}-R_{n-1}}(t)\right\} .\right.
$$

As in the proof of Theorem 2.1, letting $t \rightarrow \infty$ in (2.22) one obtains

$$
\begin{gathered}
\bar{H}_{R, N}(x, n)=\left\{\lim _{t \rightarrow \infty} \frac{V(t)}{t}\right\}\left\{\lim _{t \rightarrow \infty} \frac{1}{V(t)} \sum_{i=1}^{V(t)} I_{\left(N_{i}^{-}=n-1\right)} \delta_{i}\right\} \cdot E\left[\{S-x\}^{+}\right] \\
=\lambda *_{n-1} F\left[\{S-x\}^{+}\right] .
\end{gathered}
$$

Substituting $\lambda *_{n-1}=\frac{e_{n}}{E[S]}$ (from Theorem 2.1) into (2.23) proves the theorem. 


\section{Stochastic Ordering of Queue Length and Busy Period Distributions with Erlang Service Times and FIFO and LIFO-P/R Service Disciplines}

In this section we restrict ourselves to the queueing systems described in Section 1 with Erlang service times. Let $N_{\phi}(t)$ be the number of customers in system at time $t$ under the service discipline $\phi \varepsilon\{$ FIFO, LIFO-P/R\}. One then has the following theorem:

Theorem 3.1. If $p(n)=p, n \geq 0$, then

$$
\left.\left\{N_{\mathrm{FIFO}}(t), t \geq 0\right\} \leq s{ }^{\left\{N_{\mathrm{LIFO}-\mathrm{P} / \mathrm{R}}\right.}(t), t \geq 0\right\} .
$$

That is, for any non-decreasing functional $f$,

$$
E\left[f\left(N_{\mathrm{FIFO}}\right)\right] \leq E\left[f\left(N_{\mathrm{LIFO}-\mathrm{P} / \mathrm{R}}\right)\right],
$$

whenever the expectations exist.

Proof: The case $p=1$ has been proven, see (3.3) of Shanthikumar and Sumita (1985b). The argument there can be easily extended to the case $0<p<1$.

Let $T_{B P: \phi}$ be the first busy period of the queueing system under the service discipline $\phi \varepsilon\{F I F O, L I F O-P / R\}$. We will next provide sufficient conditions on $(p(n))$ under which $T_{B P}:$ FIFO and $T_{B P}:$ LIFO-P/R are stochastically ordered. This extends a recent result of Shanthikumar and Sumita (1985a):

Theorem 3.3:

(a) If $p(n)$ is non-decreasing in $n \geq 0$, then $T_{B P}$ : FIFO $\leq$ st $T_{B P \text { : LIFO-P/R }}$

(b) If $p(n)$ is non-increasing in $n \geq 0$, then $T_{B P: \text { FIFO }} \geq{ }_{s t} T_{B P: \text { LIFO-P/R. }}$

Proof: To facilitate the analysis we interpret the original queueing system by a bulk arrival queue where each customer brings $m$ independent tasks to be processed. Each task requires an exponentially distributed processing time with mean $E[S] / m$. On a common probability space, we will construct two such queueing systems with FIFO and LIFO-P/R service disciplines. These queueing systems will be constructed in such a way that they have the same probabilistic properties as that of the original systems and the orderings of the busy periods hold with probability one.

Let $\left(A_{i}(\omega)\right)_{i=1}^{\infty}$ be a particular realization of $\left(A_{i}\right)_{i=1}^{\infty}$ and let $\left(U_{i}\left(\omega^{*}\right)\right)_{i=1}^{\infty}$ and $\left(D_{j}\left(\omega^{*}\right)\right)_{j=1}^{\infty}$ be sample paths of two mutually independent sequences of i.i.d. uniform random variables on $(0,1)$ and arrival epochs of a Poisson process with rate $m / E[S]$. As we will soon see, the uniform random variables are used to decide on the admittance of the customers to the system and the Poisson arrival 
epochs will correspond to the service completion epochs of tasks. For this sample realization $\left(\omega, \omega^{*}\right)$, let $N_{\phi}\left(\omega, \omega^{*}, t\right)$ be the number of customers in the system at time $t$ when service policy $\phi$ is implemented. For notational convenience we will suppress $\omega$ and $\omega *$ and write $N_{\phi}(t)$ instead of $N_{\phi}(\omega, \omega *, t)$. Same convention is adapted for other variables as we1l. Let $K_{\phi}(t), N_{a: \phi}(t)$ and $N_{s: \phi}(t)$ be the number of tasks in the system, total number of customers accepted and total number of customers departed with completed service during; $(0, t]$, respectively, for service discipline $\phi$. Without loss of generality we will assume that the server busy period in both queueing systems is initiated at time zero, i.e., we let $A_{1}=0$ and $\delta_{1}=1$. Then for $\phi \varepsilon\{F I F O, L I F O-P / R\}$, we set:

$$
\left\{\begin{array}{l}
K_{\phi}(0+)=m \\
N_{\phi}(0+)=1=N_{a: \phi}(0+) \\
N_{s: \phi}(0+)=0
\end{array}\right.
$$

The queueing process is now constructed such that

$$
\left\{\begin{array}{l}
N_{\phi}\left(A_{i}+\right)=N_{\phi}\left(A_{i}-\right)+\delta_{i: \phi} \\
N_{a: \phi}\left(A_{i}+\right)=N_{a: \phi}\left(A_{i}-\right)+\delta_{i: \phi} \\
K_{\phi}\left(A_{i}+\right)=K_{\phi}\left(A_{i}-\right)+m \cdot \delta_{i: \phi},
\end{array}\right.
$$

where $\delta_{i: \phi}=I_{\left(U_{i}<p\left(N_{\phi}\left(A_{i}-\right)\right)\right)}$, and

$$
K_{\phi}\left(D_{j}+\right)=\left\{K_{\phi}\left(D_{j}-\right)-1\right\}^{+}
$$

For $\phi=$ FIFO, the task leaving at time epoch $D_{j}$ belongs to the customer who arrived the earliest among those in the system at that time while for $\phi=\mathrm{LIFO}-\mathrm{P} / \mathrm{R}$, this task belongs to the most recently arrived customer. A customer departs as soon as all of its $m$ tasks depart. If $T_{B P: \phi}$ is the first busy period,

$$
T_{B P: \phi}=\inf \left\{t: K_{\phi}(t)=0, t>0\right\} .
$$

The following lemma will be used to complete the proof. Define

$$
T^{* *}=\min \left\{T_{B P}: \mathrm{FIFO}, T_{B P}: \mathrm{LIFO}-\mathrm{P} / \mathrm{R}\right\},
$$

and

$$
W(t)=\max \left\{j: D_{j} \leq t\right\}
$$


For $t \leq T^{*}, W(t)$ is the number of tasks serviced during $(0, t]$ in both queues, since they have been busy till then.

Lemma 3.3. If $A_{i} \leq T^{*}$, then for (a)

$$
K_{\mathrm{FIFO}}\left(A_{i}^{+)} \leq K_{\mathrm{LIFO}-\mathrm{P} / \mathrm{R}}\left(A_{i}^{+}\right)\right.
$$

$$
N_{a}: \operatorname{FIFO}\left(A_{i}+\right) \leq N_{a}: \operatorname{LIFO}-\mathrm{P} / \mathrm{R}^{\left(A_{i}+\right)}
$$

and for (b) the inequality in (3.5) and (3.6) is reversed.

Proof: We prove Case (a) only. The proof for Case (b) is similar. Note that (3.5) and (3.6) are true for $i=1$. As an induction hypothesis, we assume that the lemma is true for $i$ and consider $A_{i+1} \leq T^{*}$. If the inequality in (3.6) is strict, then from (3.2) one sees that (3.6) is valid for $i+1$ also. Since

$$
K_{\phi}(t)=m \cdot N_{a: \phi}(t)-w(t), \quad t \leq T^{*}
$$

it is also clear that $(3.5)$ is valid for $i+1$. So we need to consider only the case where equality holds in (3.6). Since $N_{a: \phi}\left(A_{i}{ }^{+}\right)=N_{a}: \phi\left(A_{i+1}-\right)$, in this case $K_{\mathrm{FIFO}}\left(A_{i+1}-\right)=K_{\mathrm{LIFO}-\mathrm{P} / \mathrm{R}}\left(A_{i+1}-\right)$. Hence

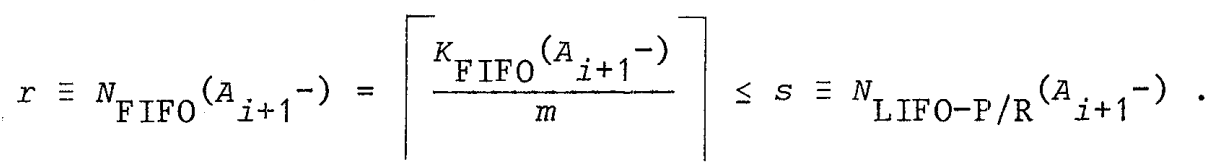

where $\lceil x\rceil$ is the smallest integer which is greater than or equal to $x$. From the monotonicity assumption for $(a), p(r) \leq p(s)$. Then from (3.2), if a customer arriving at $A_{j+1}$ is accepted into the FIFO queueing system, one customer will also be accepted into LIFO-P/R queueing system. However, an acceptance into the LIFO-P/R queueing system does not necessarily imply the acceptance of a customer into the FIFO queueing system. It is then immediately clear that $(3.5)$ and $(3.6)$ are valid for $i+1$.

Now we complete the proof of Theorem 3.2 through the following argument. Let $0<t \leq T^{*}$ and define $i *=\max \left\{i: A_{i} \leq t\right\}$. Then from (3.7) and Lemma 3.3 one sees that for case (a):

$$
\begin{aligned}
& K_{\text {FIFO }}(t)=m \cdot N_{a: F I F O}\left(A_{i *}+\right)-W(t) \\
& \quad \leq m \cdot N_{a}: \text { LIFO-P/R }\left(A_{i *}+\right)-W(t)=K_{\text {LIFO-P } / \mathrm{R}}(t) .
\end{aligned}
$$

(3.4) combined with (3.8) shows that $T_{B P: F I F O}\left(\omega, \omega^{*}\right) \leq T_{B P}$ : LIFO-P/R $\left(\omega, \omega^{*}\right)$. Case (b) follows similarly. 
Remark 3.4. When $p(n)=p, n \geq 1$, cases (a) and (b) of Theorem 3.2 apply. In this case one then has $T_{B P}$ : FIFO $\stackrel{\text { st }}{=} T_{B P}:$ LIFO-P/R.

\section{Bibliography}

[1] Cooper, R. B. and Niu, S. C. (1986): Benes's formula for M/G/1-FIFO "Explained" by preemptive-resume LIFO, J. AppI. Prob., 23, to appear.

[2] Fakinos, D. (1981): The $G / G / 1$ queueing system with a particular queue discipline, J. R. Statist. SoC. B, 43 190-196.

[3] Neuts, M. F. (1981): Matrix-GeometriC Solutions in stochastic Models, The Johns Hopkins University Press, Baltimore.

[4] Ramaswami, V. (1982): The busy period of queues which have a matrixgeometric steady state probability vector, Opsearch, 19, 238- 261.

[5] Shanthikumar, J. G. and Chandra, M. J. (1982): Application of level crossing analysis to discrete state processes in queueing systems, Naval Res. Logistics Quarterly, 29, 593-608.

[6] Shanthikumar, J. G. and Sumita, U. (1985a): On the busy period distributions of $M / G / I / K$ queues with state dependent arrivals and FCFS/LCFS-P service disciplines, J. AppI. Prob., 22, 912-919.

[7] Shanthikumar, J. G. and Sumita, U. (1985b): Convex ordering of sojourn times in single server queues: Extremal properties of FIFO and LIFO service disciplines, to appear in J. App1. Prob.

[8] Yamazaki, G. (1982): The GI/G/1 queue with 1ast-come-first-served, Ann. Inst. Statist. Math., 34, Part A, 599-604.

[9] Yamazaki, G. (1984): Invariance relations of GI/G/1 queueing systems with preemptive-resume last-come-first-served queue discipline, J. Opns. Res. Soc. of Japan, 27, 338-246.

\footnotetext{
Ushio Sumita: Graduate School of Management, University of Rochester Rochester, NY 14627 U.S.A.
} 


\section{後着順割り込み優先サービスを持つ \\ $\mathrm{G} / \mathrm{G} / 1$ 型待ち行列について}

J.G. Shanthikumar

住田潮

後着順割り込み優先サービスを持つ $G / G / 1$ 型待ち行列について考元る。顧客の到着過程につい ては，顧客が個々に到着するということだけを仮定し，独立性む含めて他の一切の制約を考えない。 顧客のサービス時間については互いに独立で同じ一般分布を持つあの之する。モデルを更に一般化す るため, 到着時に系内に $n$ 人の先客がある場合, 到着した客は確率 $p(n)$ で待ち行列飞参入し, 確率 1 - $p(n)$ で直ちに立ち去るあのとする。 $N$ より大きい $n$ 亿対して $p(n)=0$ と置くてとにより，待 合い室が有限な場合屯含まれることに注意しょう。本論文では, 上述した待ち行列について, 系内人 数の様々なエルゴード確率 (任意時刻, 客の到着時点, 客の退去時点等々)の相互関係を考察する。解 析のための道具立てとしては，サンプルパスに基づいた議論を中心にエルゴード理論が適宜応用され る。主要結果としては，時間 $t$ までの平均采内人数の極限分布が幾何分布に従うための十分条件が幾 つか示される。乙れは最近 Fakinos（1981）と山崎（1982，1984）飞よって得られた結果の搪張と なっている。更にサービス分布がアーラン型である場合には，先着順サービスが用いられた時と比較 して，系内人数，稼動期間について確率順序が存在するととが導かれる。 